\title{
Circulating MiR-19b-3p, MiR-134-5p and MiR-186-5p are Promising Novel Biomarkers for Early Diagnosis of Acute Myocardial Infarction
}

\author{
Ke-Jing Wang ${ }^{\mathrm{a}}$ Xin Zhao a,b Yu-Zhou Liü,c Qiu-Tang Zeng ${ }^{\mathrm{a}}$ Xiao-Bo Mao ${ }^{\mathrm{a}}$ \\ Song-Nan Li ${ }^{b}$ Ming Zhang ${ }^{b}$ Chao Jiang ${ }^{b}$ You Zhou ${ }^{a}$ Cheng Qian ${ }^{a}$ Kai-Ge Feng ${ }^{a}$ \\ Hong-Quan Guan ${ }^{\mathrm{a}}$ Ting-Ting Tang ${ }^{\mathrm{a}} \quad$ Xiang Cheng ${ }^{\mathrm{a}}$ Zhi-Jian Chen ${ }^{\mathrm{a}}$ \\ aLaboratory of Cardiovascular Immunology, Institute of Cardiology, Union Hospital, Tongji Medical \\ College, Huazhong University of Science and Technology, Wuhan, 'D Department of Cardiology, Beijing \\ Anzhen Hospital, Capital Medical University, Beijing, 'Department of Cardiology, The First Affiliated \\ Hospital, Zhengzhou University, Zhengzhou, China
}

\section{Key Words}

Circulating microRNAs • Acute myocardial infarction • Diagnostic biomarkers

\begin{abstract}
Background/Aims: Recent studies have shown that circulating microRNAs (miRNAs) are emerging as promising biomarkers for cardiovascular diseases. This study aimed to determine whether miR-19b-3p, miR-134-5p and miR-186-5p can be used as novel indicators for acute myocardial infarction (AMI). Methods: To investigate the kinetic expression of the three selected miRNAs, we enrolled 18 patients with AMI and 20 matched controls. Plasma samples were collected from each participant, and total RNA was extracted. Quantitative real-time PCR and ELISA assays were used to investigate the expression of circulating miRNAs and cardiac troponin I (cTnI), respectively. Plasma samples from another age- and gender-matched cohort were collected to investigate the impact of medications for AMI on the expression of the selected miRNAs. Results: Levels of plasma miR-19b-3p, miR-134-5p and miR-186-5p were significantly increased in early stage of AMI. Plasma miR-19b-3p and miR-134-5p levels reached peak expression immediately after admission (T0), whereas miR-186-5p achieved peak expression at $4 \mathrm{~h}$ after T0. All of these times were earlier than the peak for $\mathrm{cTnI}(8 \mathrm{~h}$ after T0). In addition, all three miRNAs were positively correlated with cTnI. Receiver Operating Characteristic (ROC) analysis indicated that each single miRNA showed considerable diagnostic efficiency for predicting AMI. Furthermore, combining all three miRNAs in a panel increased the efficiency of distinguishing between patients with AMI and controls. Moreover, we found that heparin and medications for AMI did not impact the expression of these
\end{abstract}

K.-J. Wang, X. Zhao and Y.-Z. Liu contributed equally to this work.

Xiang Cheng and Zhi-Jian Chen

Department of Cardiology, Institute of Cardiology, Union Hospital, Tongji Medical College, Huazhong University of Science and Technology, No.1277 Jiefang Avenue, Jianghan District, Wuhan 430022, Hubei Province, (China)

KARGER 
circulating miRNAs. Conclusion: Circulating miR-19b-3p, miR-134-5p and miR-186-5p could be considered promising novel diagnostic biomarkers for the early phase of AMI.

(C) 2016 The Author(s)

Published by S. Karger AG, Basel

\section{Introduction}

Acute myocardial infarction (AMI) is a major cause of morbidity and mortality worldwide [1]. Early and accurate diagnosis of AMI is crucial to managing the disease, circumscribing myocardial injury, and preserving heart function. Some biomarkers, such as cardiac troponins (cTnI/cTnT) and creatine kinase, have been widely used for the diagnosis of AMI during the past few decades [2,3]. However, circulating cTnI/cTnT is not an entirely specific marker for discriminating AMI from other diseases, such as severe heart failure, viral myocarditis, takotsubo cardiomyopathy, hypothyroidism, chronic kidney failure and septic shock [4-7]. Consequently, there is a clinical need for novel diagnostic biomarkers to reliably and immediately rule in or rule out AMI.

MicroRNAs (miRNAs) are a class of short ( $\sim 22$ nucleotide), single-stranded, non-coding RNAs that facilitate the down-regulation of gene expression by binding to complementary sequences in the 3' untranslated region (3' UTR) of target mRNAs [8-10]. Moreover, an accumulating number of miRNAs have been verified to be critically involved in maintaining normal heart function and pathological process involved in cardiovascular diseases [11-17]. In addition to being potent regulators of gene expression, recent studies have shown that miRNAs may also serve as circulating biomarkers for various diseases, including tumors and cardiovascular disorders, because of their remarkable stability in the blood, urine and other fluids [18-21].

The diagnostic value of cardiac-enriched miRNAs in the setting of AMI has been the focus of recent studies. Considering that AMI is a complex pathophysiological process with the involvement of various kinds of cells, the contribution of non cardiac-enriched miRNAs is worthy of equal attention. miR-19b is a member of the miR-17-92 cluster (miR$17 / 18 a / 19 a / 19 b / 20 a / 92 a)$, which is located on chromosome 13 [22, 23]. Previous studies have shown that miR-19b is involved in aging-associated heart failure and the positive regulation of cardiomyocyte hypertrophy and apoptosis by targeting atrogin-1 and MuRF-1 [24]. As a potential plasma biomarker for the diagnosis of acute pulmonary embolism, miR134 is also reported to be up-regulated in patients with acute coronary syndrome (ACS) [2527]. miR-186, which is previously reported to serve as a circulating biomarker for certain cancers $[28,29]$ and modulate apoptosis in several kinds of cells [30,31], may also facilitate the diagnosis of ACS $[26,32]$. Although all these miRNAs were not cardiac-enriched miRNAs, preliminary evidence from a recent miRNA microarray analysis revealed that the expression of miR-19b, miR-134 and miR-186 were up-regulated in patients with AMI compared to controls [33]. However, the specific expression patterns of these circulating miRNAs in patients with AMI, and their clinical significance remain unknown. In this study, we aim to assess the dynamic expressions of plasma miR-19b-3p, miR-134-5p and miR-186-5p at different time-points in the early stage of AMI, and to explore their diagnostic value.

\section{Materials and Methods}

\section{Ethics Statement}

The protocols used in the present study were conducted according to the principles expressed in the Declaration of Helsinki and approved by the Medical Ethics Committee of the Union Hospital of Huazhong University of Science and Technology. Patients were admitted to the Department of Cardiology in Union Hospital (Wuhan, China) between January 2013 and April 2014. 


\section{Cellular Physiology Cell Physiol Biochem 2016;38:1015-1029 \begin{tabular}{l|l} 
DOI: 10.1159/000443053 & $\begin{array}{l}\text { C) 2016 The Author(s). Published by S. Karger AG, Basel } \\
\text { www.karger.com/cpb }\end{array}$ \\
\hline Published ondine: March 04, 2016 Biochemistry
\end{tabular} \\ Wang et al.: Circulating MicroRNAs as Biomarkers for AMI}

Patients

There were two cohorts from which a total of 106 participants were enrolled in our study. In addition, written informed consent was obtained from all enrolled patients, and the data for clinical presentation/ history, cardiovascular risk factors and medication records were also obtained.

We enrolled 18 patients with AMI and 20 matched control subjects in the first cohort. The inclusion criteria for AMI patients were based on the 2012 ESC/AHA/ACC guidelines [34]. Briefly, the inclusion criteria were: lasting ischemic symptoms (>30 min); increased creatine kinase-MB (CK-MB) and cTnI levels that were twice the upper limit of normal; pathological Q waves; ST-T segment and T wave changes; and coronary angiography. All of the AMI patients were diagnosed for the first time and underwent a primary percutaneous coronary intervention (PCI). Coronary angiography was performed to exclude coronary heart disease (CHD) in control subjects. The exclusion criteria were as follows: previous history of cardiac diseases (MI, heart failure or cardiomyopathy), known malignancy, renal replacement therapy, surgery or skeletal muscle damage within the previous months, all of which might impact the expression of miRNAs. Moreover, we collected blood samples before and after PCI procedures to investigate the effects of heparin on plasma miRNAs.

To further investigate whether the medications used to treat AMI, including angiotensin converting enzyme inhibitors (ACEI), beta-blockers, nitrates, statins, aspirin and clopidogrel, had an impact on the expression of plasma miRNAs, we enrolled 32 patients who were using these medications (medications were administered to patients for at least one week) and 36 matched controls in the second cohort. The exclusion criteria for the second cohort were the same as for the first cohort.

Sample collection and storage

Patients who presented with acute chest pain were admitted to Union hospital, and peripheral venous blood samples from AMI patients were obtained at each time-point as follows. The initial blood sample collection time (T0) was $10.40 \pm 3.52 \mathrm{~h}$ after the onset of chest pain symptoms. Additionally, following T0, other blood samples were obtained at $4 \mathrm{~h} \pm 30 \mathrm{~min}(4 \mathrm{~h}), 8 \mathrm{~h} \pm 30 \mathrm{~min}(8 \mathrm{~h}), 12 \mathrm{~h} \pm 30 \mathrm{~min}(12 \mathrm{~h}), 24 \mathrm{~h} \pm 30$ $\min (24 \mathrm{~h}), 48 \mathrm{~h} \pm 30 \mathrm{~min}(48 \mathrm{~h})$ and $72 \mathrm{~h} \pm 30 \mathrm{~min}(72 \mathrm{~h})$.

All blood samples (4-8 mL) were collected with K2-EDTA-coated tubes (BD, New Jersey, US). All samples were treated using the following protocol: samples were stored for up to $24 \mathrm{~h}$ at $4^{\circ} \mathrm{C}$, and then a two-step centrifugation protocol $\left(1,500 \mathrm{~g}\right.$ for $15 \mathrm{~min}$ at $4^{\circ} \mathrm{C}$ and then $14,000 \mathrm{~g}$ for another $15 \mathrm{~min}$ at $\left.4^{\circ} \mathrm{C}\right)$ was initiated. After centrifugation, the plasma was extracted, aliquoted, transferred to RNase/DNase-free tubes and stored $\mathrm{at}-80^{\circ} \mathrm{C}$ for the following experiments.

\section{Plasma microRNA isolation and validation}

Using TRIzol Reagent BD (TR126, MRC, Cincinnati, US), total RNA was extracted from plasma according to the manufacturer's instructions. Briefly, frozen plasma was thawed, and then the plasma $(250 \mu \mathrm{L})$ was mixed with $750 \mu \mathrm{L}$ TRIzol and incubated for $15 \mathrm{~min}$ at room temperature to ensure complete dissociation of nucleoprotein complexes $(1 / 3, v / v)$. After chloroform was added $(200 \mu \mathrm{L})$, the mixture was vortexed vigorously for $15 \mathrm{sec}$. After extraction at room temperature (15 $\mathrm{min})$, the mixture was centrifuged at 12,000 $\mathrm{g}$ for $15 \mathrm{~min}$ at $4^{\circ} \mathrm{C}$. The upper aqueous phase was transferred to fresh reagent tubes, and then an equal volume of cold isopropanol was added and the solution was incubated at $-20^{\circ} \mathrm{C}$ overnight. All samples were centrifuged at $12,000 \mathrm{~g}$ for $15 \mathrm{~min}$ at $4^{\circ} \mathrm{C}$, and the supernatant was thrown out. Then, the RNA pellet was purged with $1 \mathrm{~mL}$ ethanol $(75 \% \mathrm{v} / \mathrm{v})$ to remove residual salt. For normalization, each sample was supplemented with 25 pM Caenorhabditi selegans miR-39 (cel-miR-39) after the addition of TRIzol, as previously reported [35].

To determine the circulating levels of miRNAs, $1 \mu \mathrm{g}$ total RNA was reverse-transcribed using a cDNA Reverse Transcription Kit (TAKARA, Japan) according to the manufacturer's protocol. Quantitative real-time PCR (qRT-PCR) were performed using a Bulge-Loop ${ }^{\mathrm{TM}}$ miRNA qRT-PCR Detection Kit (Ribobio, Guangzhou, China) and a SYBR Green PCR Master Mix Kit (TransGen Biotech, Beijing, China) with cel-miR-39 used as the normalization control. All data were analyzed using Bio-Rad CFX Manager software (Bio-Rad, CA). Cycle threshold (Ct) values were normalized to cel-miR-39 using the formula 2-(Ct [miRNA]-Ct [cel-miRNA-39]), and the $2^{-\Delta \Delta \mathrm{Ct}}$ method was used to analyze the relative expression levels of miRNAs. 


\section{Cellular Physiology Cell Physiol Biochem 2016;38:1015-1029 \\ \begin{tabular}{l|l} 
and Biochemistry & DOI: 10.1159/000443053 \\
Published online: March 04, 2016 & $\begin{array}{l}\text { (c) } 2016 \text { The Author(s). Published by S. Karger AG, Basel } \\
\text { www.karger.com/cpb }\end{array}$
\end{tabular} \\ Wang et al.: Circulating MicroRNAs as Biomarkers for AMI}

Determination of plasma cardiac troponin I levels

All plasma samples used for cTnI level determination were aliquoted and stored at $-80^{\circ} \mathrm{C}$ until further use. Subsequently, the expression level of plasma cardiac troponin I (cTnI) was determined using an immune-fluorescence diagnostics system (Abbott Diagnostics, Abbott Park, IL, USA) according to the manufacturer's directions. The normal reference range for cTnI was established to be $<0.3 \mathrm{ng} / \mathrm{ml}$.

\section{Statistical analysis}

All data were represented as the mean \pm standard deviation (SD). For normally distributed values, Student's two-sided t-test or one-way ANOVA followed by Bonferroni's multiple comparison test as a post hoc analysis were performed. In addition, Kruskal-Wallis and Mann-Whitney tests were used for statistical variables without a normal distribution. The time course expression analysis of the miRNAs and cTnI were analyzed using the repeated-measures ANOVA method. For categorical clinical variables, a Chi-Square $(\chi 2)$ test (Fisher's exact test when necessary) was used. We performed correlation analysis of the miRNAs and cTnI using Pearson's correlation coefficient.

Receiver operating characteristic (ROC) curves and the area under the ROC curves (AUC) were determined to discriminate AMI patients from control subjects and to assess the diagnostic accuracy of the selected miRNAs, respectively. A miRNA score (as the inverted-normalized miRNA signal) was calculated to represent the relative expression level of the selected miRNA in the AMI group compared to the control group. Importantly, the miRNA scores were calculated by deducting the normalized Ct from 40 and adjusted by subtracting the minimal score (so that the miRNA-scores started at 0), as previously reported [36]. The cut-off values with the largest Youden's index (sensitivity + specificity - 1) were used to evaluate the optimal diagnostic points of the miRNAs. SPSS 13.0 software (Chicago, IL, USA) was used to perform the statistical analyses, all statistical tests were two-tailed, and $\mathrm{p}<0.05$ was considered statistically significant.

\section{Results}

Baseline characteristics of the study population

In the first cohort, we assessed the baseline characteristics of 18 AMI patients and 20 control subjects (Table 1). The result showed that there were no statistical differences between the control subjects and AMI patients for most of the considered clinical variables, whereas CK-MB was markedly up-regulated in the AMI patients compared to the control subjects, which is consistent with previous reports. In addition, the medications used to treat AMI were significantly different between the AMI group and the control group.

In the second cohort, which we enrolled to explore the potential effects of medications on the expression of plasma miRNAs, there were significant differences in the history of hyper-lipidemia and the application of related medications between the two matched groups (Table 2).

The expression patterns of circulating miRNAs

We used qRT-PCR assays to investigate the expression patterns of the selected miRNAs (miR-19b-3p, miR-134-5p and miR-186-5p) in the early phase of AMI. The results showed that the expression levels of all three miRNAs were obviously up-regulated in AMI patients compared to control subjects. The expression of circulating miR-19b-3p in AMI patients relative to the controls was increased by $5.01 \pm 1.47$-fold (T0), $4.27 \pm 1.12$-fold ( $4 \mathrm{~h}$ ), $4.49 \pm$ 1.36-fold ( $8 \mathrm{~h}$ ), $3.49 \pm 0.98$-fold ( $12 \mathrm{~h}$ ), $2.79 \pm 0.86$-fold $(24 \mathrm{~h}), 1.87 \pm 0.38$-fold ( $48 \mathrm{~h}$ ), and $1.51 \pm 0.29$-fold $(72 \mathrm{~h}$ ), respectively (Fig. 1A). Likewise, the circulating level of miR-134-5p was increased by $6.00 \pm 1.69$-fold (T0), $4.19 \pm 1.14$-fold ( $4 \mathrm{~h}$ ), $3.57 \pm 1.11$-fold ( $8 \mathrm{~h}$ ), 3.18 \pm 1.14 -fold $(12 \mathrm{~h}$ ), $2.03 \pm 0.29$-fold $(24 \mathrm{~h}), 2.25 \pm 0.73$-fold $(48 \mathrm{~h})$ and $1.62 \pm 0.17$-fold $(72$ h), respectively (Fig. 1B). Relative to levels in the control subjects, circulating miR-186-5p was increased by $1.96 \pm 0.42$-fold (T0), $2.48 \pm 0.45$-fold $(4 \mathrm{~h}), 1.83 \pm 0.55$-fold ( $8 \mathrm{~h}$ ), $1.48 \pm$ 0.27 -fold $(12 \mathrm{~h}$ ), $1.39 \pm 0.23$-fold ( $24 \mathrm{~h}$ ), $1.29 \pm 0.15$-fold $(48 \mathrm{~h}$ ), and $1.13 \pm 0.08$-fold $(72 \mathrm{~h}$ ), respectively (Fig. 1C).

Meanwhile, circulating miR-19b-3p and miR-134-5p both achieved peak expression at T0; however, circulating miR-186-5p reached peak expression at $4 \mathrm{~h}$ after T0. Compared to 
Table 1. Clinical characteristics of AMI patients and the control subjects. BMI, Body mass index; DM, Diabetes mellitus; WBC, white blood cell; SBP, systolic blood pressure; DBP, diastolic blood pressure; TC, total cholesterol; TG, total triglyceride; HDL, high-density lipoprotein; LDL, low-density lipoprotein; Cr, creatinine; CK-MB, Creatine Kinase-MB. Data are shown as the mean $\pm \mathrm{SD}$; ${ }^{*} \mathrm{p}<0.05$ and $* *$ $\mathrm{p}<0.01$ for AMI group vs. control group
Table 2. Clinical characteristics of the enrolled subjects in the second cohort. BMI, Body mass index; DM, Diabetes mellitus; WBC, white blood cell; TC, total cholesterol; TG, total triglyceride; HDL, high-density lipoprotein; LDL, low-density lipoprotein; $\mathrm{Cr}$, creatinine; ACE, angiotensin-converting enzyme. Data are shown as the mean $\pm \mathrm{SD}$; $*<0.05$ and $* *$ $p<0.01$ in the medication group $v s$. the control group

\begin{tabular}{|c|c|c|c|}
\hline Variable & $\begin{array}{l}\text { AMI group } \\
(n=18)\end{array}$ & $\begin{array}{c}\text { Control group } \\
(\mathrm{n}=20)\end{array}$ & $P$-value \\
\hline Male/Female (n/n) & $10 / 8$ & $7 / 13$ & 0.33 \\
\hline Age (years) & $57.86 \pm 10.75$ & $54.36 \pm 11.30$ & 0.34 \\
\hline BMI $\left(\mathrm{kg} / \mathrm{m}^{2}\right)$ & $24.79 \pm 2.37$ & $24.14 \pm 2.58$ & 0.43 \\
\hline \multicolumn{4}{|l|}{ Smoking status } \\
\hline Current smoker $(\%)$ & $3(17 \%)$ & $2(10 \%)$ & 0.65 \\
\hline Former smoker $(\%)$ & $6(33 \%)$ & $5(25 \%)$ & 0.72 \\
\hline Hypertension, n (\%) & $9(50 \%)$ & $5(25 \%)$ & 0.18 \\
\hline DM, n (\%) & $3(17 \%)$ & $1(5 \%)$ & 0.33 \\
\hline WBC $\left(\times 10^{9} / \mathrm{L}\right)$ & $10.23 \pm 3.37$ & $7.02 \pm 1.42$ & $<0.01^{* *}$ \\
\hline $\mathrm{SBP}(\mathrm{mmHg})$ & $119.42 \pm 16.54$ & $121.79 \pm 17.72$ & 0.67 \\
\hline $\mathrm{DBP}(\mathrm{mmHg})$ & $77.92 \pm 13.42$ & $80.54 \pm 12.29$ & 0.53 \\
\hline Heart rate (beats/minutes) & $72.42 \pm 11.45$ & $78.05 \pm 13.15$ & 0.17 \\
\hline $\mathrm{TC}(\mathrm{mmol} / \mathrm{L})$ & $4.64 \pm 0.78$ & $4.33 \pm 0.64$ & 0.19 \\
\hline $\mathrm{HDL}(\mathrm{mmol} / \mathrm{L})$ & $1.29 \pm 0.19$ & $1.33 \pm 0.24$ & 0.58 \\
\hline LDL $(\mathrm{mmol} / \mathrm{L})$ & $2.82 \pm 0.93$ & $2.64 \pm 0.69$ & 0.50 \\
\hline $\mathrm{TG}(\mathrm{mmol} / \mathrm{L})$ & $1.53 \pm 0.72$ & $1.35 \pm 0.73$ & 0.45 \\
\hline $\mathrm{Cr}(\mathrm{umol} / \mathrm{L})$ & $76.27 \pm 12.47$ & $71.28 \pm 10.27$ & 0.19 \\
\hline CK-MB (IU/L) & $132.67 \pm 47.25$ & $7.56 \pm 1.47$ & $<0.01^{* *}$ \\
\hline \multicolumn{4}{|l|}{ Medications } \\
\hline ACE inhibitors (\%) & $11(61 \%)$ & $3(15 \%)$ & $<0.01^{* *}$ \\
\hline Beta-blockers (\%) & $15(83 \%)$ & $4(20 \%)$ & $<0.01^{* *}$ \\
\hline Nitrates $(\%)$ & $14(78 \%)$ & / & $<0.01^{* *}$ \\
\hline Statins $(\%)$ & $18(100 \%)$ & $7(35 \%)$ & $<0.01^{* *}$ \\
\hline Aspirin (\%) & $18(100 \%)$ & $5(25 \%)$ & $<0.01^{* *}$ \\
\hline Clopidogrel (\%) & $18(100 \%)$ & / & $<0.01^{* *}$ \\
\hline
\end{tabular}

\begin{tabular}{lllc}
\hline Variable & $\begin{array}{c}\text { Medication group } \\
(\mathrm{n}=32)\end{array}$ & $\begin{array}{c}\text { Control group } \\
(\mathrm{n}=36)\end{array}$ & $p$-value \\
\hline Male/Female (n/n) & $18 / 14$ & $24 / 12$ & 0.38 \\
Age (years) & $55.62 \pm 9.17$ & $58.57 \pm 11.54$ & 0.25 \\
BMI (kg/m²) & $24.17 \pm 2.34$ & $25.07 \pm 2.95$ & 0.17 \\
Smoking status & & & \\
$\quad$ Current smoker (\%) & $8(25 \%)$ & $4(11 \%)$ & 0.20 \\
$\quad$ Former smoker (\%) & $12(38 \%)$ & $6(17 \%)$ & 0.05 \\
History of hypertension, n (\%) & $14(44 \%)$ & $8(22 \%)$ & 0.06 \\
History of hyperlipidaemia, $\mathrm{n} \%)$ & $24(75 \%)$ & $6(17 \%)$ & $<0.01^{* *}$ \\
Current level of TC (mmol/L) & $4.69 \pm 0.92$ & $4.33 \pm 0.81$ & 0.09 \\
Current level of HDL (mmol/L) & $1.38 \pm 0.22$ & $1.44 \pm 0.21$ & 0.25 \\
Current level of LDL (mmol/L) & $2.96 \pm 1.03$ & $2.57 \pm 0.88$ & 0.10 \\
Current level of TG (mmol/L) & $1.53 \pm 0.72$ & $1.35 \pm 0.73$ & 0.31 \\
DM, n (\%) & $4(13 \%)$ & $2(6 \%)$ & 0.41 \\
WBC (x 109 /L) & $7.35 \pm 1.05$ & $6.84 \pm 1.42$ & 0.10 \\
Heart rate (beats/minutes) & $76.34 \pm 11.50$ & $74.37 \pm 9.57$ & 0.44 \\
Cr (umol/L) & $73.42 \pm 15.62$ & $67.15 \pm 13.31$ & 0.08 \\
Medications & & & \\
$\quad$ ACE inhibitors (\%) & $14(44 \%)$ & $7(19 \%)$ & $0.03^{*}$ \\
$\quad$ Beta-blockers (\%) & $8(25 \%)$ & $2(6 \%)$ & $0.04^{*}$ \\
$\quad$ Nitrates (\%) & $5(16 \%)$ & $/$ & $0.02^{*}$ \\
$\quad$ Statins (\%) & $24(75 \%)$ & $6(17 \%)$ & $<0.01^{* *}$ \\
$\quad$ Aspirin (\%) & $18(56 \%)$ & $5(14 \%)$ & $<0.01^{* *}$ \\
$\quad$ Clopidogrel (\%) & $4(13 \%)$ & $/$ & $0.04^{*}$ \\
\hline
\end{tabular}


Fig. 1. The expression levels of circulating miRNAs and cTnI in AMI patients and control subjects. The expression levels of circulating miR-19b3p (A); miR-134-5p (B); and miR-186-5p (C) in AMI patients and control subjects. The expression levels of circulating cTnI (D) in AMI patients and control subjects. AMI, acute myocardial infarction; CRTL, controls; T0, the initial time point of blood sample collection after admission. Data are shown as the mean $\pm \mathrm{SD}$; $* p<0.05$ and ${ }^{* *} p<0.01$ vs. control subjects.
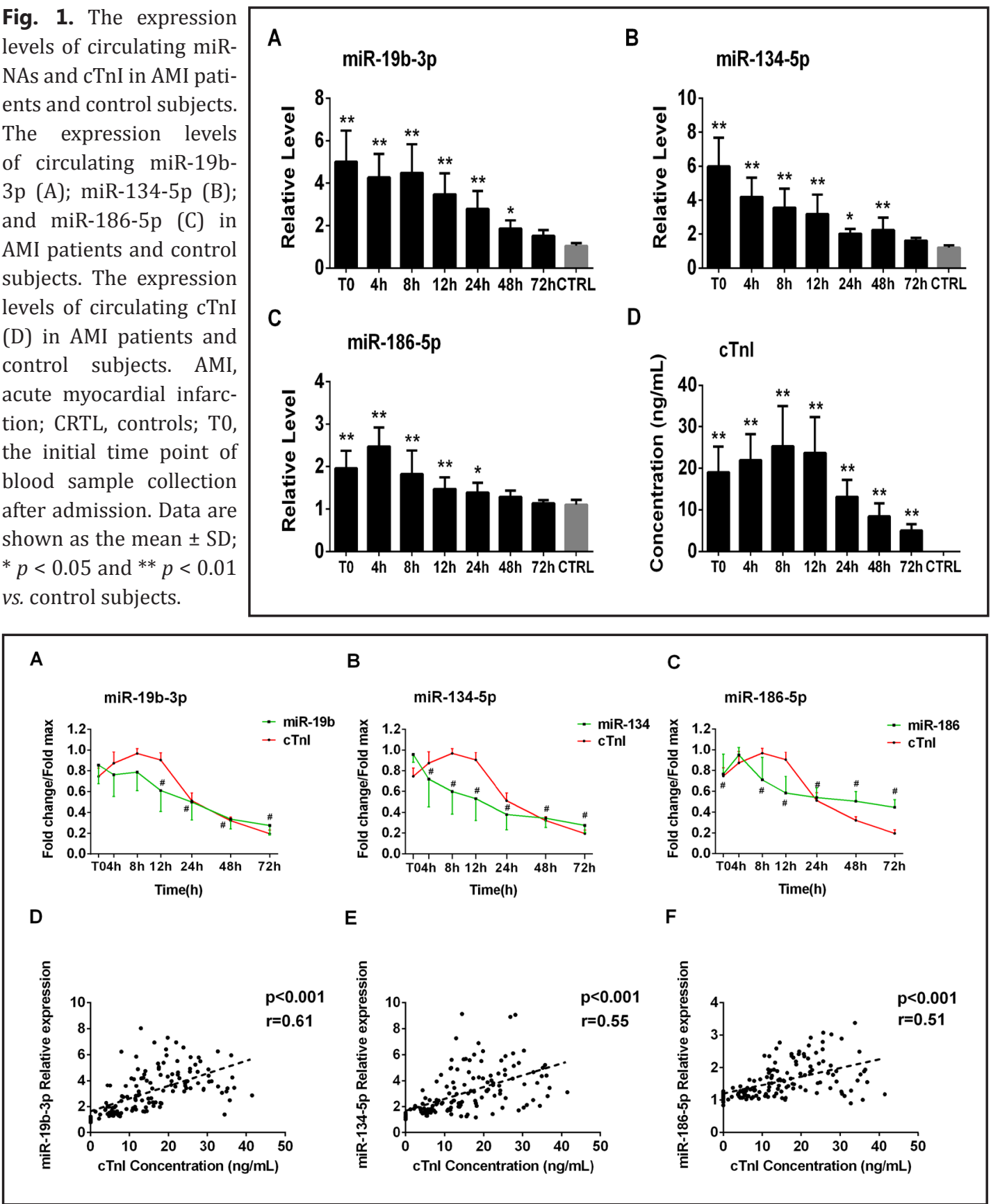

Fig. 2. The kinetic expressions of circulating miRNAs and cTnI in AMI patients and the relationships between them. (A) the expression patterns of circulating miR-19b-3p and cTnI in the AMI group; (B) the expression patterns of circulating miR-134-5p and cTnI in the AMI group; (C) the expression patterns of circulating miR-186-5p and cTnI in the AMI group; (D) the correlation between circulating miR-19b-3p and cTnI; (E) the correlation between circulating miR-134-5p and cTnI; and (F) the correlation between circulating miR-186-5p and cTnI. AMI, acute myocardial infarction; CRTL, controls. Data are shown as the mean \pm SD; \# $p<0.05$ vs. peak level in the AMI patients.

control subjects, miR-19b-3p and miR-134-5p remained an increase expression until $48 \mathrm{~h}$ after T0, whereas miR-186-5p returned to the baseline level at $24 \mathrm{~h}$ after T0. 


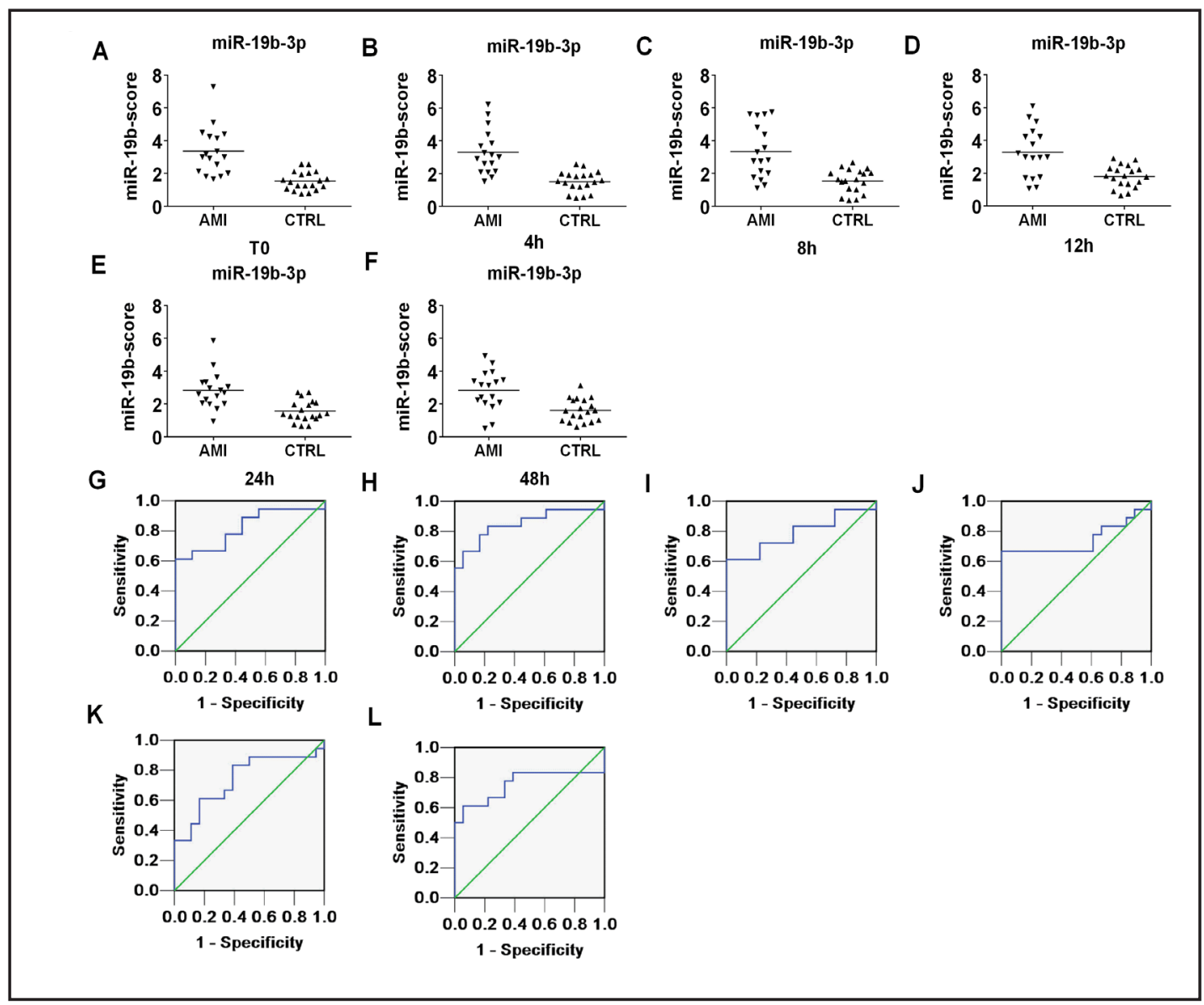

Fig. 3. Discriminatory power of circulating miR-19b-3p scores. The miR-19b-3p scores are presented as

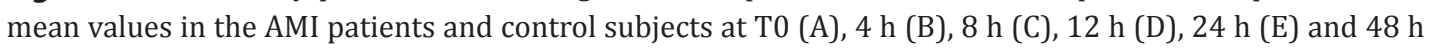
(F), respectively. The receiver operator characteristic (ROC) curves for miR-19b-3p at T0 (G), $4 \mathrm{~h}(\mathrm{H}), 8 \mathrm{~h}(\mathrm{I})$, $12 \mathrm{~h}(\mathrm{~J}), 24 \mathrm{~h}(\mathrm{~K})$ and $48 \mathrm{~h}(\mathrm{~L})$, respectively. AMI, acute myocardial infarction; CRTL, controls.

\section{The expression pattern of plasma cTnI}

Plasma cTnI levels were determined at different time points using the same samples that were used for the analysis of miRNAs. The results showed that the expression level of cTnI in AMI patients was increased, relative to the control subjects, by $938 \pm 304$-fold (T0), $1083 \pm 308$-fold $(4 \mathrm{~h}), 1247 \pm 477$-fold $(8 \mathrm{~h}$ ), $1165 \pm 428$-fold $(12 \mathrm{~h}), 645 \pm 201$-fold $(24 \mathrm{~h}$ ), $412 \pm 156$-fold ( $48 \mathrm{~h}$ ) and $245 \pm 77$-fold (72 h), respectively (Fig. 1D). In addition, plasma cTnI levels achieved peak expression at $8 \mathrm{~h}$ after T0, which was later than the peak for miR19b-3p, miR-134-5p and miR-186-5p.

The correlation between circulating miRNAs and cTnI

Then, we investigated the relationship between plasma miRNA and cTnI levels. The results indicated that all three selected circulating miRNAs, miR-19b-3p $(r=0.61)$ miR-134$5 p(r=0.55)$ and miR-186-5p $(r=0.51)$, exhibited a significantly positive correlation with cTnI (Fig. 2A-2F).

The diagnostic specificity and sensitivity of miRNAs in AMI

To further explore the applicability of using circulating miRNAs as potential diagnostic biomarkers for AMI, we converted the expression levels of the miRNAs into miRNA scores and performed ROC analysis, as previously reported. 


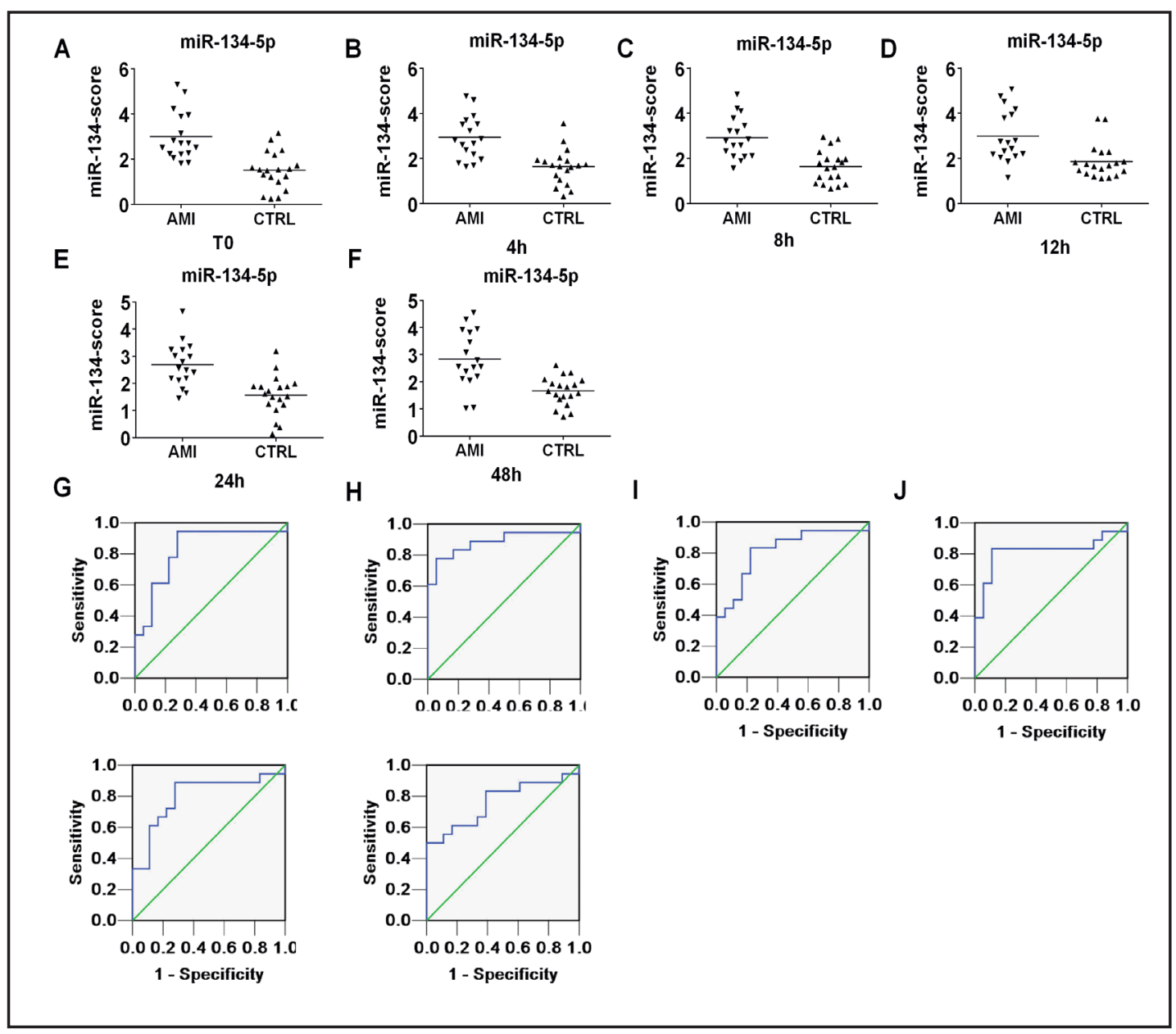

Fig. 4. Discriminatory power of circulating miR-134-5p scores. The miR-134-5p scores are presented as

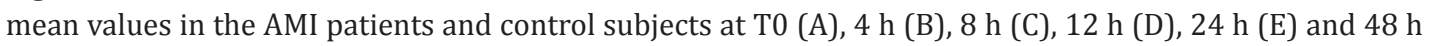
(F), respectively. The receiver operator characteristic (ROC) curves for miR-134-5p at T0 (G), $4 \mathrm{~h}(\mathrm{H}), 8 \mathrm{~h}(\mathrm{I})$, $12 \mathrm{~h}(\mathrm{~J}), 24 \mathrm{~h}(\mathrm{~K})$ and $48 \mathrm{~h}(\mathrm{~L})$, respectively. AMI, acute myocardial infarction; CRTL, controls.

The mean scores for miR-19b-3p were 3.17 (T0), 3.12 (4 h), 3.14 (8h), 3.09 (12 h), 2.67 $(24 \mathrm{~h})$ and $2.66(48 \mathrm{~h})$ in the AMI group and $1.45,1.44,1.45,1.71,1.48$ and 1.53 , respectively, in the control group (Fig. 3A-3F). The mean scores for miR-134-5p were 2.84 (T0), 2.77 (4 h), $2.75(8 \mathrm{~h}), 2.82(12 \mathrm{~h}), 2.54(24 \mathrm{~h})$ and 2.68 (48 h) in the AMI group and 1.43, 1.55, 1.55, 1.77, 1.48 and 1.57, respectively, in the control group (Fig. 4A-4F). The mean scores for miR186-5p were 3.30 (T0), 3.37 ( $4 \mathrm{~h}), 3.16(8 \mathrm{~h}), 2.70(12 \mathrm{~h})$ and $2.73(24 \mathrm{~h})$ in the AMI group and 1.68, 1.65, 1.57, 1.46 and 1.67, respectively, in the control group (Fig. 5A-5E). However, when we combined the three circulating miRNAs, the mean scores for the compositedmiRNAs were 3.20 (T0), 3.03 (4 h), 2.94 (8 h), 2.82 (12 h) and 2.69 (24 h) in the AMI group and $1.59,1.52,1.50,1.62$ and 1.65, respectively, in the control group (Fig. 6A-6E).

The results of the ROC curve analysis indicated that miR-19b-3p (Fig. 3G-3L), miR134-5p (Fig. 4G-4L) and miR-186-5p (Fig. 5F-5J) separately showed a moderate power for differentiating AMI patients from control subjects at various time points in the early phase of AMI. However, when combined the three miRNAs, the composited-miRNAs scores presented markedly improved ability to distinguish between the AMI and control groups at T0, $4 \mathrm{~h}, 8 \mathrm{~h}, 12 \mathrm{~h}$ and $24 \mathrm{~h}$ (Table 3). Moreover, the composited-miRNAs showed higher AUC values than the single miRNAs at all times course (Fig. 6F-6J). 


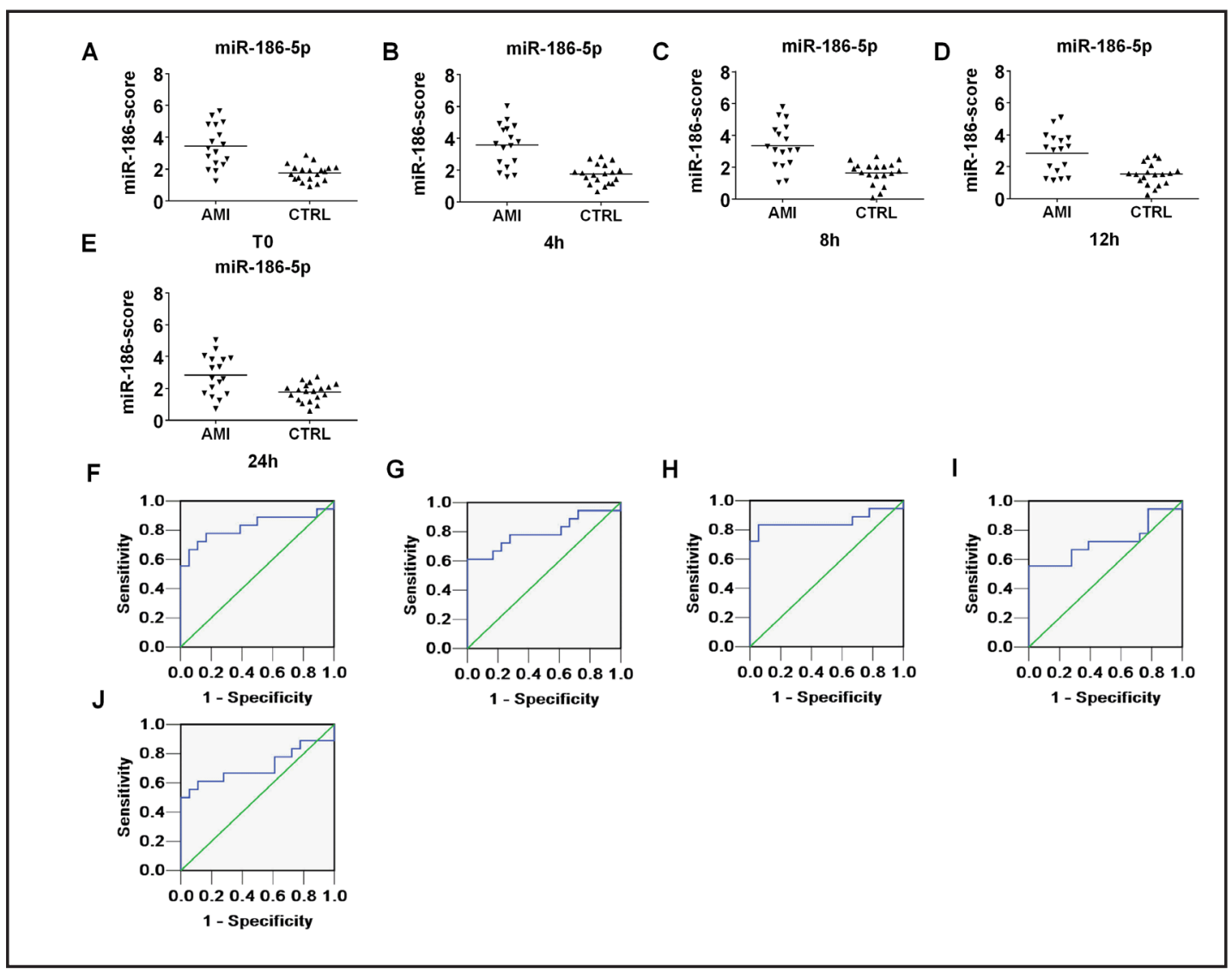

Fig. 5. Discriminatory power of circulating miR-186-5p scores. The miR-186-5p scores are presented as mean values in the AMI patients and control subjects at T0 (A), $4 \mathrm{~h}(\mathrm{~B}), 8 \mathrm{~h}(\mathrm{C}), 12 \mathrm{~h}(\mathrm{D})$ and $24 \mathrm{~h}(\mathrm{E})$, respectively. The receiver operator characteristic (ROC) curves for miR-186-5p at T0 (F), $4 \mathrm{~h}(\mathrm{G}), 8 \mathrm{~h}(\mathrm{H}), 12 \mathrm{~h}$ (I) and $24 \mathrm{~h}(\mathrm{~J})$, respectively. AMI, acute myocardial infarction; CRTL, controls.

The effect of heparin on circulating levels of the selected miRNAs

Previous studies have indicated that heparin might impact the circulating level of miRNA expression [37]. Consequently, we investigated whether heparin impacted the plasma levels of the selected miRNAs during the PCI procedure in AMI patients. The results showed that the expression levels of all three miRNAs were higher in pre-PCI plasma than post-PCI plasma of AMI patients. However, this difference did not reach statistical significance, which suggested that heparin might not impact the expression of circulating levels of miR-19b-3p, miR-134-5p or miR-186-5p (Fig. 7A-7C).

The effect of medications for AMI on circulating levels of the selected miRNAs

We noticed that the application of medications for AMI represented a significant difference between the AMI group and the control group that might impact the expression of plasma miRNAs. Therefore, to investigate the effect of medications on the expression of the selected miRNAs, we enrolled another age- and gender-matched cohort, and measured the expression levels of miR-19b-3p, miR-134-5p and miR-186-5p in plasma. Our findings showed that these medications (ACEI, beta-blockers, nitrates, statins, aspirin and clopidogrel) for AMI did not affect the expression of the selected miRNAs (Fig. 7D-7F).

\section{Discussion}

In the present study, we delineated the temporal expression profile of three non heartand muscle-specific miRNAs at the early stage of AMI, and by performing ROC curve analysis, 


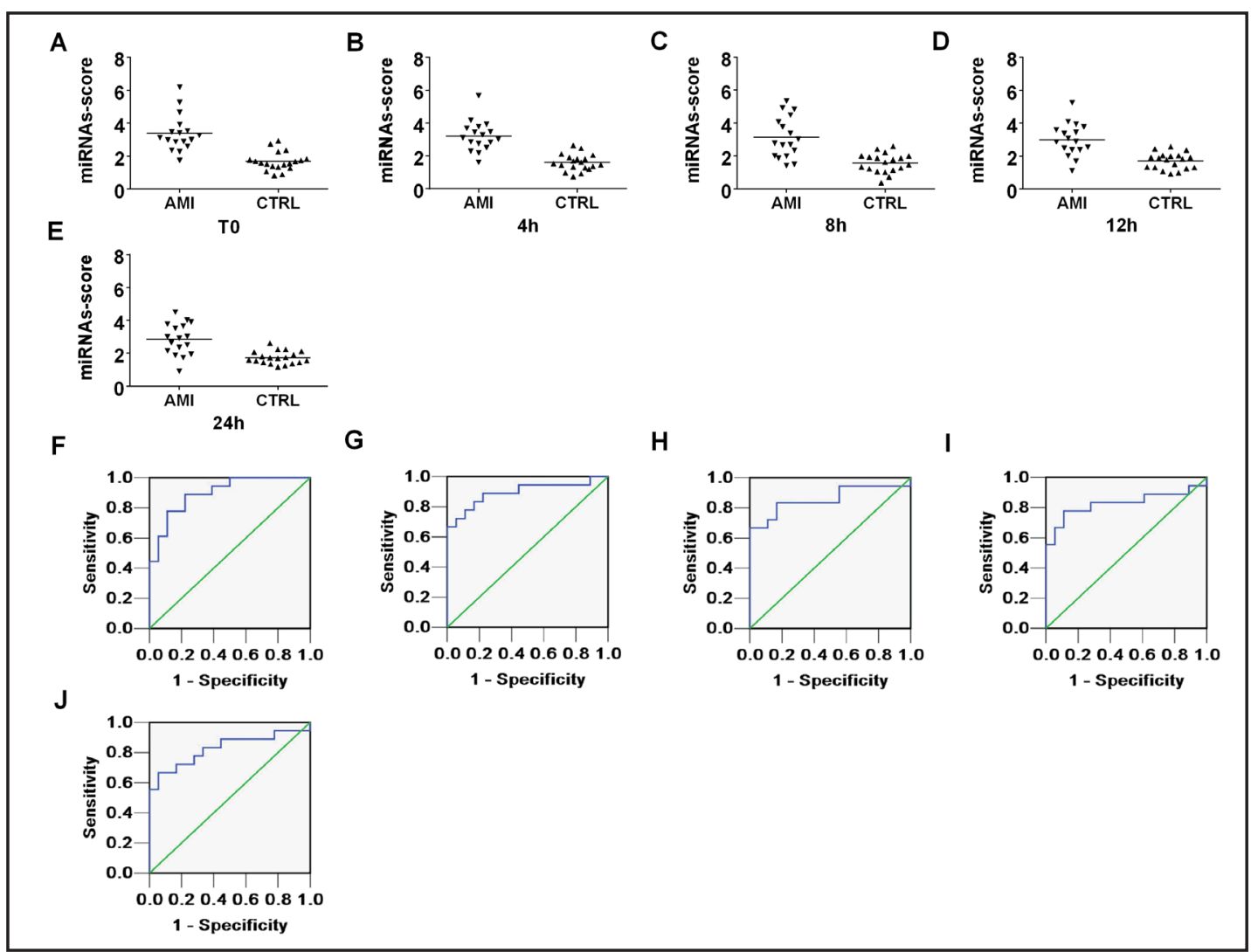

Fig. 6. Discriminatory power of composited-miRNA scores. The composited-miRNA scores are presented as mean values in the AMI patients and control subjects at T0 (A), $4 \mathrm{~h} \mathrm{(B),} 8 \mathrm{~h} \mathrm{(C),} 12 \mathrm{~h}(\mathrm{D})$ and $24 \mathrm{~h}(\mathrm{E})$, respectively. The receiver operator characteristic (ROC) curves for combined miRNA at T0 (F), $4 \mathrm{~h}(\mathrm{G}), 8 \mathrm{~h}$ $(\mathrm{H}), 12 \mathrm{~h}(\mathrm{I})$ and $24 \mathrm{~h}(\mathrm{~J})$, respectively. The composited-miRNA scores include the scores for miR-19b-3p, miR-134-5p and miR-186-5p. AMI, acute myocardial infarction; CRTL, controls.

Table 3. The diagnostic value of circulating miRNAs for AMI. AMI, acute myocardial infarction; Composited-score, the combination of miR-19b-3p, miR-134-5p and miR186-5p scores; AUC, area under the ROC curve; $95 \% \mathrm{Cl}$, 95\% confidence interval

\begin{tabular}{lllllccc}
\hline Time point & miRNAs & AUC & $95 \%$ CI & $\mathrm{p}$ value & Cut off value & Sensitivity & Specificity \\
\hline T0 & miR-19b-3p & 0.821 & $0.678-0.964$ & $\mathrm{p}=0.001$ & 1.9695 & 0.722 & 0.667 \\
& miR-134-5p & 0.827 & $0.682-0.972$ & $\mathrm{p}=0.001$ & 2.1145 & 0.778 & 0.778 \\
& miR-186-5p & 0.824 & $0.674-0.974$ & $\mathrm{p}=0.001$ & 2.0696 & 0.778 & 0.778 \\
& Composited-score & 0.898 & $0.799-0.997$ & $\mathrm{p}<0.001$ & 2.1739 & 0.889 & 0.778 \\
4h & miR-19b-3p & 0.849 & $0.849-0.984$ & $\mathrm{p}<0.001$ & 1.9310 & 0.833 & 0.778 \\
& miR-134-5p & 0.883 & $0.759-1.000$ & $\mathrm{p}<0.001$ & 1.6646 & 0.833 & 0.833 \\
& miR-186-5p & 0.796 & $0.641-0.952$ & $\mathrm{p}=0.002$ & 2.0469 & 0.778 & 0.722 \\
\multirow{3}{*}{$8 \mathrm{~h}$} & Composited-score & 0.895 & $0.783-1.000$ & $\mathrm{p}<0.001$ & 2.0032 & 0.889 & 0.778 \\
& miR-19b-3p & 0.790 & $0.633-0.947$ & $\mathrm{p}=0.003$ & 1.9138 & 0.722 & 0.722 \\
& miR-134-5p & 0.818 & $0.674-0.962$ & $\mathrm{p}=0.001$ & 2.0035 & 0.833 & 0.778 \\
& miR-186-5p & 0.858 & $0.713-1.000$ & $\mathrm{p}<0.001$ & 1.7989 & 0.833 & 0.833 \\
& Composited-score & 0.858 & $0.724-0.992$ & $\mathrm{p}<0.001$ & 1.8570 & 0.833 & 0.833 \\
& miR-19b-3p & 0.744 & $0.564-0.924$ & $\mathrm{p}=0.012$ & 2.1390 & 0.667 & 0.667 \\
& miR-134-5p & 0.818 & $0.661-0.975$ & $\mathrm{p}=0.001$ & 1.8580 & 0.833 & 0.833 \\
& miR-186-5p & 0.722 & $0.545-0.900$ & $\mathrm{p}=0.023$ & 1.6435 & 0.667 & 0.667 \\
& Composited-score & 0.827 & $0.676-0.978$ & $\mathrm{p}=0.001$ & 2.0205 & 0.883 & 0.722 \\
& miR-19b-3p & 0.741 & $0.573-0.909$ & $\mathrm{p}=0.014$ & 1.8378 & 0.667 & 0.667 \\
& miR-134-5p & 0.799 & $0.644-0.954$ & $\mathrm{p}=0.002$ & 2.1740 & 0.778 & 0.722 \\
& miR-186-5p & 0.713 & $0.531-0.895$ & $\mathrm{p}=0.029$ & 2.0075 & 0.667 & 0.722 \\
& Composited-score & 0.827 & $0.683-0.972$ & $\mathrm{p}=0.001$ & 1.9346 & 0.778 & 0.722 \\
& miR-19b-3p & 0.756 & $0.580-0.932$ & $\mathrm{p}=0.009$ & 2.0701 & 0.722 & 0.667 \\
& miR-134-5p & 0.762 & $0.599-0.925$ & $\mathrm{p}=0.007$ & 2.3182 & 0.667 & 0.667 \\
\hline
\end{tabular}

we demonstrated that circulating miR-19b-3p, miR-134-5p and miR-186-5p may serve as novel candidate diagnostic biomarkers at the early stage of AMI. 




Fig. 7. The impact of heparin and medications for AMI on circulating level of miRNAs. The expression of circulating miR-19b-3p (A), miR-134-5p (B), and miR-186-5p (C) in the pre-PCI and post-PCI plasma of AMI patients. The level of circulating miR-19b-3p (D), miR-134-5p (E), and miR-186-5p (F) in the plasma of the medication group and the control group. AMI, acute myocardial infarction; CRTL, controls; Medications, medication group. Data are shown as the mean $\pm \mathrm{SD} ;{ }^{* *} \mathrm{p}<0.01$ vs. control subjects.

So far, an increasing number of circulating miRNAs, including heart-, vascular- and endothelium-enriched miRNAs, have been explored as novel candidate biomarkers for various cardiovascular diseases, including atrial fibrillation (AF), coronary artery disease (CAD), heart failure (HF), heart transplant rejection, takotsubo cardiomyopathy, acute pulmonary embolism (APE) and pulmonary hypertension (PAH) [38]. Most of the published studies regarding circulating miRNA biomarkers for AMI have mainly concentrated on cardiac-derived miRNAs (e.g., miR-1/133a-b/208a/499) [33, 39]. It is worth mentioning that a variety of physiological and pathological changes occur in the courses of AMI, including endothelial dysfunction, plaque rupture, platelet aggregation, coronary thrombosis and myocardial cell necrosis $[40,41]$. There is no doubt that it is equally important for us to explore the expression patterns and potential contributions of the numerous miRNAs deriving from other cell types involved in AMI processes.

The present study shows that the expression levels of circulating miR-19b-3p, miR-134$5 p$ and miR-186-5p were significantly up-regulated in the early phase of AMI. In addition, both miR-19b-3p and miR-134-5p achieved peak expression at T0, whereas miR-186-5p reached peak expression at $4 \mathrm{~h}$ after T0, which was all earlier than the peak time for cTnI expression ( $8 \mathrm{~h}$ after T0). Moreover, all three miRNAs were positively correlated with cTnI, and circulating miR-19b-3p showed the strongest association with cTnI. Each of the miRNAs, miR-19b-3p, miR-134-5p and miR-186-5p, revealed a moderate ability to discriminate the AMI group from the control group. However, when combined all three miRNAs, the compositedmiRNAs presented a higher discriminatory power than any of the miRNAs alone, indicating that the composited-miRNAs displayed improved accuracy in identifying AMI. Meanwhile, in the present study, all three selected miRNAs presented a gradual declining trend after their peak expression in the early phase of AMI. However, heparin and medications used to treat AMI were not responsible for these decreases.

Recent studies have shed some light upon the pathophysiological roles of studied miRNAs, which may implicate their potential involvement in coronary diseases. It has been reported that miR-19b induces endothelial cell dysfunction via suppression of peroxisome 
proliferator-activated receptor $\gamma$ coactivator $1 \alpha$ (PGC-1 $\alpha$ ) during the progression of atherosclerosis and that it promotes macrophage cholesterol accumulation, foam cell formation and aortic atherosclerotic development by targeting ATP-binding cassette transporter A1 (ABCA1) [42, 43]. In addition, miR-19b has been found to be upregulated in plasma of unstable angina pectoris (UAP) patients, and may play an anti-thrombotic role by targeting tissue factor (TF) [44], which is an essential pro-coagulant protein. Immunity is another well established regulator of acute coronary events [41], and previous studies have shown that the miR-17-92 cluster also plays crucial roles in regulating various immune responses by promoting CD4+ $\mathrm{T}$ cell activation, proliferation, survival, Th1 differentiation and Th17-mediated inflammation, while inhibiting Th2 and iTreg differentiation [45-48]. miR-134 had been reported to be a brain-specific miRNA, and regulate ischemia/reperfusion injury-mediated neuronal cell death by targeting heat shock protein A12B (HSPA12B) and cyclic AMP response element-binding protein (CREB) [49, 50]. Interestingly, recent studies indicated that miR-134 might be used as a potential biomarker of coronary artery calcification, UAP or AMI [51]. Furthermore, recently published studies showed that miR186 was up-regulated in AMI or UAP patients, and may have potential diagnostic value in combination with a few other miRNAs [26, 32]. Collectively, existed evidence implies that miR-19b may play pivotal roles in the course of ACS/AMI. However, the contributions of miR134 and miR-186 in the process of AMI remain largely unexplored. Therefore, further studies would be necessary to investigate whether studied miRNAs are mechanistically involved in AMI, apart from their roles as circulating biomarkers.

There are some limitations to our present study. Firstly, the study involves a relatively small sample size, and larger clinical studies will be needed in the future to confirm the diagnostic value of miR-19b-3p, miR-134-5p and miR-186-5p for AMI. Secondly, given that ACS encompasses the clinical entities of AMI and UAP, which represent different progressive stages on the same pathological substrates, therefore, it would remain to be elucidated by future studies whether studied miRNAs could further discriminate between AMI and other acute coronary conditions. In addition, it has been recently discovered that exosomemediated transfer of miRNAs may be involved in cell-to-cell communication $[20,52,53]$. However, the underlying functions of these three selected circulating miRNAs in intracellular communication and their possible roles in the pathophysiological processes of AMI remain unknown.

In summary, our present study investigated, for the first time, the dynamic expressions of circulating miR-19b-3p, miR-134-5p and miR-186-5p in the early phase of AMI. ROC analysis suggested that circulating miR-19b-3p, miR-134-5p and miR-186-5p may be considered novel and promising biomarkers for early diagnosis of AMI. Moreover, a multi-miRNA panal including these three selected miRNAs may present even greater diagnostic value for AMI.

\section{Acknowledgments}

This work was supported by a grant from the National Natural Science Foundation of China (No. 81300146 and 81200177) and Beijing Natural Science Foundation (No. 7144207 and 7132088).

\section{Disclosure Statement}

There are no conflicts of interest.

\section{References}

1 Lopez AD, Mathers CD, Ezzati M, Jamison DT, Murray CJ: Global and regional burden of disease and risk factors, 2001: Systematic analysis of population health data. Lancet 2006;367:1747-1757. 


\section{Cellular Physiology Cell Physiol Biochem 2016;38:1015-1029 \begin{tabular}{l|l} 
and Biochemistry 10.1159/000443053 & $\begin{array}{l}\text { D } 2016 \text { The Author(s). Published by S. Karger AG, Basel } \\
\text { www.karger.com/cpb }\end{array}$ \\
\hline
\end{tabular}}

Wang et al.: Circulating MicroRNAs as Biomarkers for AMI

Katus HA, Remppis A, Neumann FJ, Scheffold T, Diederich KW, Vinar G, Noe A, Matern G, Kuebler W: Diagnostic efficiency of troponin T measurements in acute myocardial infarction. Circulation 1991;83:902912.

3 White HD, Chew DP: Acute myocardial infarction. Lancet 2008;372:570-584.

4 Abbas NA, John RI, Webb MC, Kempson ME, Potter AN, Price CP, Vickery S, Lamb EJ: Cardiac troponins and renal function in nondialysis patients with chronic kidney disease. Clin Chem 2005;51:2059-2066.

5 Rosjo H, Varpula M, Hagve TA, Karlsson S, Ruokonen E, Pettila V, Omland T: Circulating high sensitivity troponin T in severe sepsis and septic shock: Distribution, associated factors, and relation to outcome. Intensive Care Med 2011;37:77-85.

6 Finsterer J, Stollberger C, Krugluger W: Cardiac and noncardiac, particularly neuromuscular, disease with troponin-T positivity. Neth J Med 2007;65:289-295.

7 Jensen JK, Atar D, Mickley H: Mechanism of troponin elevations in patients with acute ischemic stroke. Am J Cardiol 2007;99:867-870.

8 Doench JG, Sharp PA: Specificity of microRNA target selection in translational repression. Genes Dev 2004;18:504-511.

9 Ambros V: The functions of animal microRNAs. Nature 2004;431:350-355.

10 Lee Y, Ahn C, Han J, Choi H, Kim J, Yim J, Lee J, Provost P, Radmark O, Kim S, Kim VN: The nuclear RNase III Drosha initiates microRNA processing. Nature 2003;425:415-419.

11 Thum T, Catalucci D, Bauersachs J: MicroRNAs: Novel regulators in cardiac development and disease. Cardiovasc Res 2008;79:562-570.

12 Melo SF, Fernandes T, Barauna VG, Matos KC, Santos AA, Tucci PJ, Oliveira EM: Expression of MicroRNA-29 and collagen in cardiac muscle after swimming training in Myocardial-Infarcted rats. Cell Physiol Biochem 2014;33:657-669.

13 Xu Y, Zhu W, Sun Y, Wang Z, Yuan W, Du Z: Functional network analysis reveals versatile MicroRNAs in human heart. Cell Physiol Biochem 2015;36:1628-1643.

14 Zhao X, Wang K, Liao Y, Zeng Q, Li Y, Hu F, Liu Y, Meng K, Qian C, Zhang Q Guan H, Feng K, Zhou Y, Du Y, Chen Z: MicroRNA-101a inhibits cardiac fibrosis induced by hypoxia via targeting TGFbetaRI on cardiac fibroblasts. Cell Physiol Biochem 2015;35:213-226.

15 Wang H, Bei Y, Shi J, Xiao J, Kong X: Non-Coding RNAs in cardiac aging. Cell Physiol Biochem 2015;36:16791687.

16 Carrillo ED, Sampieri R, Hernandez A, Garcia MC, Sanchez JA: MiR-132 regulates rem expression in cardiomyocytes during Long-Term beta-Adrenoceptor agonism. Cell Physiol Biochem 2015;36:141-154.

17 Wang Y, Men M, Yang W, Zheng H, Xue S: MiR-31 downregulation protects against cardiac Ischemia/ Reperfusion injury by targeting protein kinase c epsilon (PKCepsilon) directly. Cell Physiol Biochem 2015;36:179-190.

18 Chen X, Ba Y, Ma L, Cai X, Yin Y, Wang K, Guo J, Zhang Y, Chen J, Guo X, Li Q, Li X, Wang W, Zhang Y, Wang J, Jiang X, Xiang Y, Xu C, Zheng P, Zhang J, Li R, Zhang H, Shang X, Gong T, Ning G, Wang J, Zen K, Zhang J, Zhang CY: Characterization of microRNAs in serum: A novel class of biomarkers for diagnosis of cancer and other diseases. Cell Res 2008;18:997-1006.

19 Mitchell PS, Parkin RK, Kroh EM, Fritz BR, Wyman SK, Pogosova-Agadjanyan EL, Peterson A, Noteboom J, O’Briant KC, Allen A, Lin DW, Urban N, Drescher CW, Knudsen BS, Stirewalt DL, Gentleman R, Vessella RL, Nelson PS, Martin DB, Tewari M: Circulating microRNAs as stable blood-based markers for cancer detection. Proc Natl Acad Sci USA 2008;105:10513-10518.

20 Gupta SK, Bang C, Thum T: Circulating microRNAs as biomarkers and potential paracrine mediators of cardiovascular disease. Circ Cardiovasc Genet 2010;3:484-488.

21 Cortez MA, Bueso-Ramos C, Ferdin J, Lopez-Berestein G, Sood AK, Calin GA: MicroRNAs in body fluids--the mix of hormones and biomarkers. Nat Rev Clin Oncol 2011;8:467-477.

22 Qin DN, Qian L, Hu DL, Yu ZB, Han SP, Zhu C, Wang X, Hu X: Effects of miR-19b overexpression on proliferation, differentiation, apoptosis and Wnt/beta-catenin signaling pathway in P19 cell model of cardiac differentiation in vitro. Cell Biochem Biophys 2013;66:709-722.

23 Du W, Pan Z, Chen X, Wang L, Zhang Y, Li S, Liang H, Xu C, Zhang Y, Wu Y, Shan H, Lu Y: By targeting Stat3 microRNA-17-5p promotes cardiomyocyte apoptosis in response to ischemia followed by reperfusion. Cell Physiol Biochem 2014;34:955-965. 


\section{Cellular Physiology Cell Physiol Biochem 2016;38:1015-1029

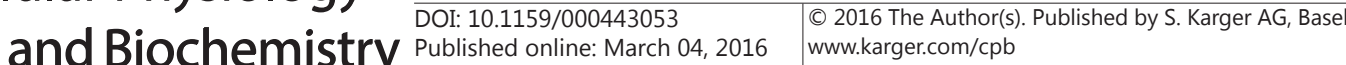 \\ Wang et al.: Circulating MicroRNAs as Biomarkers for AMI}

24 Song DW, Ryu JY, Kim JO, Kwon EJ, Kim DH: The miR-19a/b family positively regulates cardiomyocyte hypertrophy by targeting atrogin-1 and MuRF-1. Biochem J 2014;457:151-162.

25 Xiao J, Jing ZC, Ellinor PT, Liang D, Zhang H, Liu Y, Chen X, Pan L, Lyon R, Liu Y, Peng LY, Liang X, Sun Y, Popescu LM, Condorelli G, Chen YH: MicroRNA-134 as a potential plasma biomarker for the diagnosis of acute pulmonary embolism. J Transl Med 2011;9:159.

26 Li C, Fang Z, Jiang T, Zhang Q, Liu C, Zhang C, Xiang Y: Serum microRNAs profile from genome-wide serves as a fingerprint for diagnosis of acute myocardial infarction and angina pectoris. BMC Med Genomics 2013;6:16.

27 He F, Lv P, Zhao X, Wang X, Ma X, Meng W, Meng X, Dong S: Predictive value of circulating miR-328 and miR134 for acute myocardial infarction. Mol Cell Biochem 2014;394:137-144.

28 Summerer I, Unger K, Braselmann H, Schuettrumpf L, Maihoefer C, Baumeister P, Kirchner T, Niyazi M, Sage E, Specht HM, Multhoff G, Moertl S, Belka C, Zitzelsberger H: Circulating microRNAs as prognostic therapy biomarkers in head and neck cancer patients. Br J Cancer 2015;113:76-82.

29 Verma AM, Patel M, Aslam MI, Jameson J, Pringle JH, Wurm P, Singh B: Circulating plasma microRNAs as a screening method for detection of colorectal adenomas. Lancet 2015;385:S100.

30 He W, Feng J, Zhang Y, Wang Y, Zang W, Zhao G: MicroRNA-186 inhibits cell proliferation and induces apoptosis in human esophageal squamous cell carcinoma by targeting SKP2. Lab Invest DOI:10.1038/ labinvest.2015.134.

31 Zheng J, Li XD, Wang P, Liu XB, Xue YX, Hu Y, Li Z, Li ZQ, Wang ZH, Liu YH: CRNDE affects the malignant biological characteristics of human glioma stem cells by negatively regulating miR-186. Oncotarget 2015;6:25339-25355.

32 Zeller T, Keller T, Ojeda F, Reichlin T, Twerenbold R, Tzikas S, Wild PS, Reiter M, Czyz E, Lackner KJ, Munzel T, Mueller C, Blankenberg S: Assessment of microRNAs in patients with unstable angina pectoris. Eur Heart J 2014;35:2106-2114.

33 D'Alessandra Y, Devanna P, Limana F, Straino S, Di Carlo A, Brambilla PG, Rubino M, Carena MC, Spazzafumo L, De Simone M, Micheli B, Biglioli P, Achilli F, Martelli F, Maggiolini S, Marenzi G, Pompilio G, Capogrossi MC: Circulating microRNAs are new and sensitive biomarkers of myocardial infarction. Eur Heart J 2010;31:2765-2773.

34 Thygesen K, Alpert JS, Jaffe AS, Simoons ML, Chaitman BR, White HD, Thygesen K, Alpert JS, White HD, Jaffe AS, Katus HA, Apple FS, Lindahl B, Morrow DA, Chaitman BR, Clemmensen PM, Johanson P, Hod H, Underwood R, Bax JJ, Bonow JJ, Pinto F, Gibbons RJ, Fox KA, Atar D, Newby LK, Galvani M, et al.: Third universal definition of myocardial infarction. J Am Coll Cardiol 2012;60:1581-1598.

35 Huang S, Chen M, Li L, He M, Hu D, Zhang X, Li J, Tanguay RM, Feng J, Cheng L, Zeng H, Dai X, Deng Q, Hu FB, Wu T: Circulating MicroRNAs and the occurrence of acute myocardial infarction in Chinese populations. Circ Cardiovasc Genet 2014;7:189-198.

36 Goren Y, Kushnir M, Zafrir B, Tabak S, Lewis BS, Amir O: Serum levels of microRNAs in patients with heart failure. Eur J Heart Fail 2012;14:147-154.

37 Kaudewitz D, Lee R, Willeit P, McGregor R, Markus HS, Kiechl S, Zampetaki A, Storey RF, Channon KM, Mayr $\mathrm{M}$ : Impact of intravenous heparin on quantification of circulating microRNAs in patients with coronary artery disease. Thromb Haemost 2013;110:609-615.

38 Dimmeler S, Zeiher AM: Circulating microRNAs: Novel biomarkers for cardiovascular diseases? Eur Heart J 2010;31:2705-2707.

39 Cheng C, Wang Q, You W, Chen M, Xia J: MiRNAs as biomarkers of myocardial infarction: A meta-analysis. Plos One 2014;9:e88566.

40 Fuster V, Moreno PR, Fayad ZA, Corti R, Badimon JJ: Atherothrombosis and high-risk plaque: Part I: Evolving concepts. J Am Coll Cardiol 2005;46:937-954.

41 Crea F, Liuzzo G: Pathogenesis of acute coronary syndromes. J Am Coll Cardiol 2013;61:1-11.

42 Lv YC, Tang YY, Peng J, Zhao GJ, Yang J, Yao F, Ouyang XP, He PP, Xie W, Tan YL, Zhang M, Liu D, Tang DP, Cayabyab FS, Zheng XL, Zhang DW, Tian GP, Tang CK: MicroRNA-19b promotes macrophage cholesterol accumulation and aortic atherosclerosis by targeting ATP-binding cassette transporter A1. Atherosclerosis 2014;236:215-226.

43 Xue Y, Wei Z, Ding H, Wang Q Zhou Z, Zheng S, Zhang Y, Hou D, Liu Y, Zen K, Zhang CY, Li J, Wang D, Jiang X: MicroRNA-19b/221/222 induces endothelial cell dysfunction via suppression of PGC-1alpha in the progression of atherosclerosis. Atherosclerosis 2015;241:671-681. 


\section{Cellular Physiology Cell Physiol Biochem 2016;38:1015-1029 \begin{tabular}{ll|l} 
DOI: 10.1159/000443053 & O 2016 The Author(s). Published by S. Karger AG, Basel \\
www.karger.com/cpb
\end{tabular} \\ Wang et al.: Circulating MicroRNAs as Biomarkers for AMI}

44 Li S, Ren J, Xu N, Zhang J, Geng Q, Cao C, Lee C, Song J, Li J, Chen H: MicroRNA-19b functions as potential anti-thrombotic protector in patients with unstable angina by targeting tissue factor. J Mol Cell Cardiol 2014;75:49-57.

45 Jiang S, Li C, Olive V, Lykken E, Feng F, Sevilla J, Wan Y, He L, Li QJ: Molecular dissection of the miR-17-92 cluster's critical dual roles in promoting Th1 responses and preventing inducible Treg differentiation. Blood 2011;118:5487-5497.

46 Sasaki K, Kohanbash G, Hoji A, Ueda R, McDonald HA, Reinhart TA, Martinson J, Lotze MT, Marincola FM, Wang E, Fujita M, Okada H: MiR-17-92 expression in differentiated T cells - implications for cancer immunotherapy. J Transl Med 2010;8:17.

47 Xiao C, Srinivasan L, Calado DP, Patterson HC, Zhang B, Wang J, Henderson JM, Kutok JL, Rajewsky K: Lymphoproliferative disease and autoimmunity in mice with increased miR-17-92 expression in lymphocytes. Nat Immunol 2008;9:405-414.

48 Liu SQ Jiang S, Li C, Zhang B, Li QJ: MiR-17-92 cluster targets phosphatase and tensin homology and Ikaros Family Zinc Finger 4 to promote TH17-mediated inflammation. J Biol Chem 2014;289:12446-12456.

49 Huang W, Liu X, Cao J, Meng F, Li M, Chen B, Zhang J: MiR-134 regulates ischemia/reperfusion injuryinduced neuronal cell death by regulating CREB signaling. J Mol Neurosci 2015;55:821-829.

50 Chi W, Meng F, Li Y, Li P, Wang G, Cheng H, Han S, Li J: Impact of microRNA-134 on neural cell survival against ischemic injury in primary cultured neuronal cells and mouse brain with ischemic stroke by targeting HSPA12B. Brain Res 2014;1592:22-33.

51 Liu W, Ling S, Sun W, Liu T, Li Y, Zhong G, Zhao D, Zhang P, Song J, Jin X, Xu Z, Song H, Li Q, Liu S, Chai M, Dai Q, He Y, Fan Z, Zhou YJ, Li Y: Circulating microRNAs correlated with the level of coronary artery calcification in symptomatic patients. Sci Rep 2015;5:16099.

52 Creemers EE, Tijsen AJ, Pinto YM: Circulating microRNAs: Novel biomarkers and extracellular communicators in cardiovascular disease? Circ Res 2012;110:483-495.

53 Valadi H, Ekstrom K, Bossios A, Sjostrand M, Lee JJ, Lotvall JO: Exosome-mediated transfer of mRNAs and microRNAs is a novel mechanism of genetic exchange between cells. Nat Cell Biol 2007;9:654-659. 